Distribution NIPER--55I

DE92 001010

\title{
TREATING PARAFFIN DEPOSITS IN PRODUCING OIL WELLS
}

Topical Report

\author{
By \\ Leo Noll
}

January 1992

Work Performed Under Cooperative Agreement No. FC22-83FE60149

\author{
Prepared for \\ U. S. Department of Energy \\ Assistant Secretary for Fossil Energy \\ Jerry Casteel, Project Manager \\ Bartlesville Project Office \\ P. O. Box 1398 \\ Bartlesville, OK 74005
}

Prepared by

IIT Research Institute

National Institute for Petroleum and Energy Research

P. O. Box 2128

Bartlesville, OK 74005 


\section{TABLE OF CONTENTS}

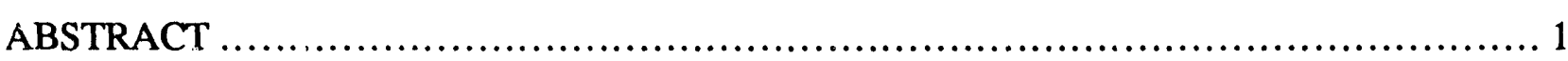

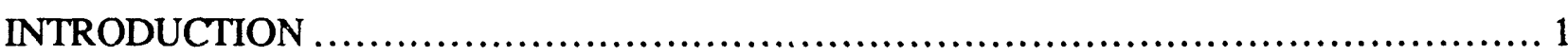

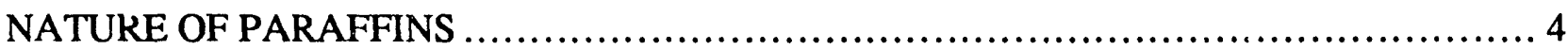

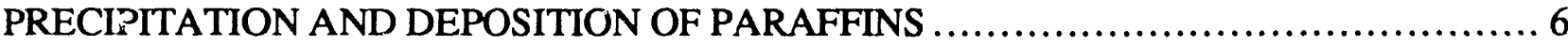

Deposition of Paraffins ................................................................ 7

Laboratory Techniques for Evaluating Paraffin Problems.............................. 7

Results of Deposition Studies............................................................ 10

Critique of the Cold Finger and Flow Deposition Tests .............................. 12

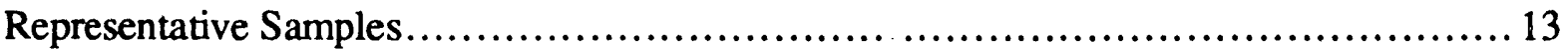

Accumulation of Paraffin ............................................................. 13

OPERATION PROCEDURES TO PREVENT PARAFFIN ACCUMULATION ............... 14

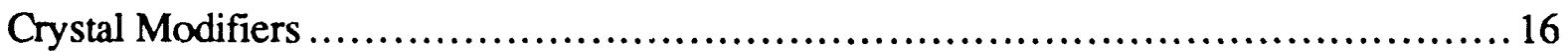

Crystal Modifiers Used in Pipelines..............................................................18

METHODS OF TREATING PARAFFIN ACCUMULATIONS ............................. 19

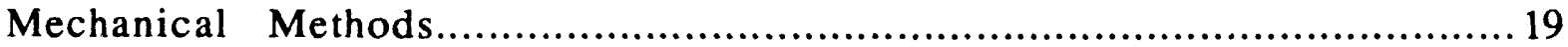

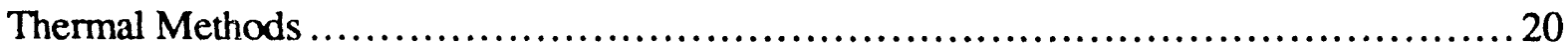

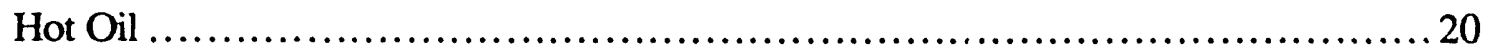

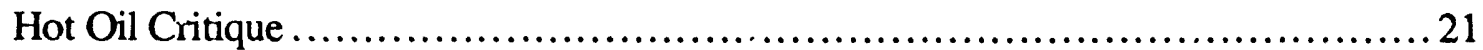

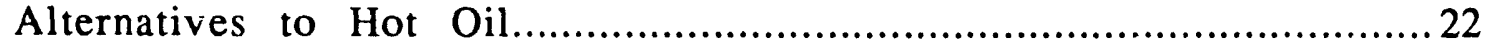

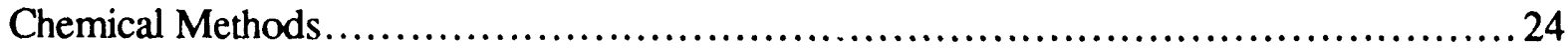

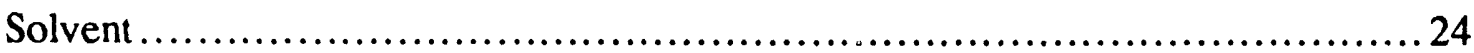

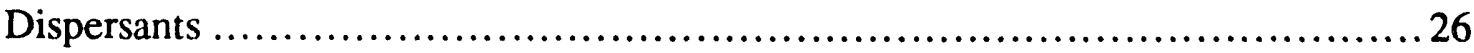

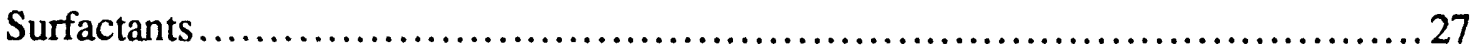

Conclusion to Chemical Treatments .................................................. 29

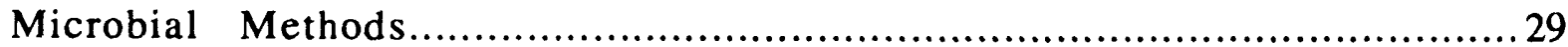

PROCEDURES IN TREATING A PARAFFIN PROBLEM ...................................3 30

ENVIRONMENTAL CONCERNS IN WELL TREATMENT FOR PARAFFIN

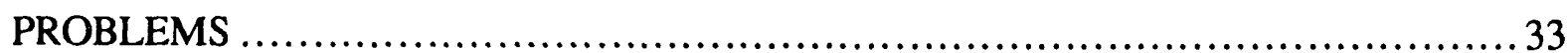

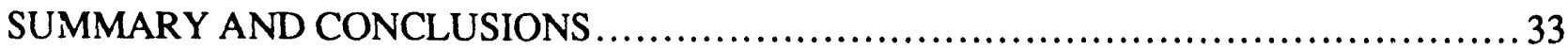

Recommendations and Areas for Further Study ................................... 34

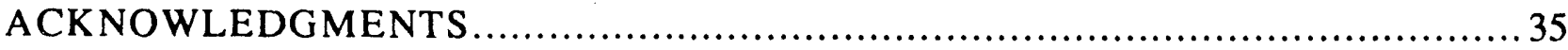

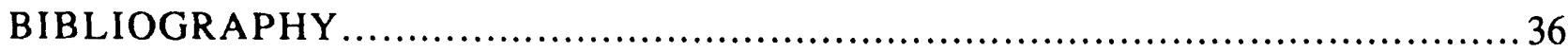




\title{
TREATING PARAFFIN DEPOSITS IN PRODUCING OIL WELLS
}

\author{
By Leo Noll
}

\begin{abstract}
Paraffin deposition has been a problem for operators in many areas since the beginning of petroleum production from wells. An extensive literature search on paraffin problems and methods of control has been carried out, and contact was made with companies which provide chemicals to aid in the treatment of paraffin problems. A discussion of the nature of paraffins and the mechanisms of this deposition is presented. The methods of prevention and treatment of paraffin problems are summarized. Suggested procedures for handling paraffin problems are provided. Suggestions for areas of further research and testing are given.
\end{abstract}

\section{INTRODUCTION}

It is the nature of many crude oils that they deposit waxy materials called "paraffin" which congeal at cooler temperatures or are so viscous that production is difficult. The paraffin which deposits in various parts of a well is a carbonaceous material which is not soluble or dispersible by crude oil under the conditions where deposition occurs. This 'paraffin' normally consists of highmolecular-weight paraffin hydrocarbons - both straight-chain and branched; resins and asphaltic materials of undetermined nature; occluded oil and water, and possibly sand and silt. Paraffin varies in consistency from that of petroleum jelly to that of a hard wax. Deposits are usually black, although lighter colors are sometimes observed. Studies have shown that its melting point is somewhat higher than that of commercial paraffin wax, and it is ordinarily less soluble in solvents that dissolve commercial paraffin wax (Uren, 1953). Recovery is impeded by accumulation of such waxy residues that tend to clog the pores of reservoir rock, well-casing perforations and screens, and tubing through which the oil flows. When crude oil is cooled, the temperature at which wax crystals begin to separate from solution is called the "cloud point." If the crude is very dark, it is usually impossible to see the onset of crystal formation, but a sudden increase of viscosity indicates the cloud point. As the crude continues to cool, small wax crystals form an interlocking network that suppurts the liquid constituents, and a temperature is finally reached ai which the oil will not flow when tilted to a horizontal position in a bottle. This temperature is called the "pourpoint." 
Bucaram (1967) reported that of 69 oil producing areas in 19 states, moderate to severe paraffin problems occurred in 59 of these areas.

Paraffin accumulations in producing oil fields may be grouped into five separate classes (Brown 1940): (1) paraffin in the tubing of flowing wells; (2) paraffin in the tubing of pumping wells; (3) paraffin in flow lines; (4) paraffin in stock tanks; and (5) paraffin on sand faces or perforated liner.

In the tubing of flowing wells, paraffin deposits produce abnormal production declines, complete killing of wells, and increased difficulty in running subsurface instruments. A principal cause is cooling by gas expansion and conduction of heat to the surrounding formation. The tendency of flowing wells to surge is one of the prime reasons for paraffin accumulation. The effects of deposits in pumping wells are to produce increased wear on pumping equipment, increased power consumption, added difficulty in pulling rods, and failure of rods to fall; also paraffin deposits lead to production declines, rod failure, and split tubing. A major cause of deposition is loss of heat to wellbore and loss of volatile components. Accumulation of paraffin in flowlines also cause unnatural production-rate declines in both flowing and pumping wells, stuffing box failures, extra power consumption, and increased wear on pumping equipment. Paraffin deposits in stock tanks is impossible to market "as is." and therefore represents a loss of revenue. Bottoms have been used as lease road-surfacing material or burned in pits. Paraffin deposits on sand faces or perforated liners reduce production. This problem is hard to detect because production decline caused by paraffin deposition is often mistaken for normal decline. Paraffin is often present in old wells where a marked reduction in pressure has released light ends. Vacuum pumps may aggravate the situation.

Paraffin accumulation in wells may result from any one of a variety of causes, but the most important factor is a reduction of temperature. The chilling effect on oil resulting from rapid expansion of associated gas in the immediate vicinity of a weilbore is a common cause of paraffin deposition. A reduction in pressure reduces the amount of solution gas; the loss of gas reduces the solubility of the solid hydrocarbons in the liquid. The rapid loss in pressure as oil approaches the wellbore through the pores of the reservoir rock may cause wax deposition by both the cooling effect and the loss of light ends. Cooling of the oil as it comes to the surface is a common cause of paraffin deposition. 
If water is present in petroleum in reservoir rock or in a well, conditions that tend to cause emulsification will also promote wax deposition and accumulation. Suspended particles of inorganic silt apparently serve as nuclei about which wax deposit and oil and water emulsion form.

Evaporation of the lighter constituents of oil during the release of dissolved natural gas is another common cause of paraffin deposition. Gas vaporizing from oil, or rising in the form of bubbles through accumulated oil in a well, often with considerable agitation of the fluid, removes the lighter fractions, leaving behind the heavier oil residues. The oil eventually becomes supersaturated with dissolved wax-forming hydrocarbons, and paraffin crystallizes out. If oil is not maintained at a constant level in a well, alternate wetting and drying of the walls as the fluid periodically rises and falls will result in gradual wax accumulation. The result is comparable with that which would be obtained by repeatedly painting the walls of a well with molten paraffin.

Deposition of wax is most serious in older partially depleted fields where the gas pressure is no longer sufficient to keep the pores of the productive sand open. The wall rocks become progressively more and more impervious by deposition of wax within their pore spaces until the wells become practically sealed off from the producing strata. The evidence indicates that, in extreme cases, paraffin accumulations may extend through the reservoir rock for distances of several feet from the wellbore.

Although wax may separate from oil, it will not necessarily be deposited on sand, pipe, rods, or other objects but it remain suspended in the oil. Some factors leading to the accumulation of paraffins include: (1) alternate coating and draining of oil from surfaces; (2) the production of a large amount of gas, since the gas tends to be produced in a spray which causes a film of oil to coat the surface; and (3) pipe surface being much cooler than the oil which tends to cause the wax. precipitate and adhere directly on the surface.

Treatments of the wax problem usually fall into four categories: (1) mechanical; (2) thermal, usually involving hot fluids, although sometimes maintaining higher pressure in flow lines and/or thermal insulation of tubular goods to maintain tubing temperature above the cloud point is beneficial; (3) chemical including the use of solvents, wax crystal modifiers, and paraffin dispersers; and (4) combinations of the above. 
In addition to the above treatments, the oil well can at times be operated in such a way as to minimize paraffin problems. Most operators use some method to keep the sand covered by fluid at all times. Although this is helpful, it does not cure all paraffin problems at the sand face. The oil needs to be produced with a minimum of gas while maintaining a steady flow of oil.

The paraffin problem is widespread enough and is severe enough that some companies are advertising materials which sound remarkably like snake oil. For example, an anonymous reporter (American Oil \& Gas Reporter, 1989) referred to a material which would convert solid petrolvum forms into liquid by leaching.

Removal of wax from wells and flowlines can account for significant additional operating costs. The operating conditions that allow waxes to precipitate in a wellbore must be identified and deposition rates must be estimated, sc that remedial efforts can be evaluated and selected and the costs associated with the removal of wax deposits may be determined. On the positive side, waxy crude oils which tend to have paraffin problems also tend to be low sulfur crudes (Price, 1971; Uhde and Kopp, 1971).

\section{NATURE OF PARAFFINS}

There were early efforts to understand the nature of paraffins in petroleum production. In an early monograph, Mills (1923) reported that paraffins are generally made up of wax, oil, and up to $20 \%$ water (brine) and inorganic silt. While Bucaram (1967) found that paraffin waxes comprised 40 to $60 \%$ of a deposit in well tubing. Comparing the properties to common commercial wax, he reminded his readers that commercial wax is quite soluble in organic solvents such as kerosine at $85^{\circ} \mathrm{F}$, soft paraffin is soluble at $122^{\circ} \mathrm{F}$; while hard wax of higher melting point has a low solubility even at $122^{\circ} \mathrm{F}$. Reistle and Blade (1932) remarked that the term 'paraffin' as used to describe this problem refers to the deposit of carbonaceous material which is not soluble or dispersible by the crude oil under the conditions where deposition occurs. The 'paraffin' normally consists of highmolecular-weight paraffin hydrocarbons - both straight-chain and branched; resins and asphaltic materials of undetermined nature; occluded oil and water, and possibly sand and silt. In consistency, the deposit may vary from a soft, sticky material to one which is hard and brittle. Deposits are usually black, although lighter colors sometimes are observed." They further noted that "deposits of crude wax or paraffin that accumulate in flow lines, in oil strings of wells, and on the face and in pores of the producing sand consist of very small wax crystals that tend to agglomerate and forn granular particles of wax about the size of the grains of table salt. Deposited 
paraffin also contains gums, resins, asphaltic material, crude oil, sand, silt, and in many instances water, and vary in consistency from a mushy liquid to a firm hard wax, depending primarily upon the amount of oil present. Because oil gradually drains from the wax particles, the hardness of the paraffin deposit and the quantity of oil associated with the wax depends upon the length of time over which accumulation takes place, and the manner in which it was deposited. The paraffins found in different wells in the same field may vary in composition, since conditions causing the deposition vary with each individual well."

Wright, (1951) remarked that the number of different compounds and types of waxes found in paraffin are dependent upon the character of the crude oil. Oil is mostly mechanically trapped in the paraffin, held between wax grains. If a large amount of oil is present the paraffin tends to be soft, semi-fluid and more readily affected by heat. If very little oil is present, the paraffin is hard and less plastic; in this case an increase in temperature does not have much effect on the plasticity until the melting point of the wax is approached. The gums and resins are normally reddish-brown aromatic compounds in solution in crude oil. Their presence in paraffin waxes is probably due partly to their adsorption by the wax crystals. Gums and resins normally comprise 10 to $15 \%$ of paraffin deposit. The asphalt content of paraffin is normally very small. The wax portion of paraffin deposits generally consists of straight- or branched-chain saturated hydrocarbons, with carbon numbers of about 18 to 60 . Straight-chain compounds with 18 to 30 carbon atoms with molecular weights of 250 to 450 daltons, have melting points of $100^{\circ}$ to $140^{\circ} \mathrm{F}$, and form macrocrystalline solids (McCall et al., 1984). These crystals are typically large plate or needleshaped structures, which tend to agglomerate. Microcrystalline waxes form much smaller crystals and tend to consist of straight-chain compounds of 40 to 60 carbon number and branched or cyclic compounds. These compounds have melting points in the range of $140^{\circ}$ to $190^{\circ} \mathrm{F}$. When wax is deposited in a well, the higher melting waxes separate first, mixed with an amount of waxes of lower melting points depending upon the extent to which the oil was cooled or evaporated while deposition took place. The straight-chain aliphatics are worst offenders, forming clearly defined needle crystals which clump together. Branched-chain compounds tend to form microcrystals which do show much less tendency to stick to each other. (Shock et al., 1955.) Price (1971) noted that when a waxy fluid was cooled below its cloud point, wax crystals formed and began to agglomerate. As the temperature was further reduced, crystal agglomeration reached the point at which a loose gel structure was formed. This gel structure could be broken down by the action of shear, but tended to reform on standing. The wax crystal habit was dependent on the crude oil, rate of cooling, and degree of agitation during cooling, among other variables. 
Nathan (1955) classified the carbonaceous fractions of paraffin deposits as: (1) soluble in cold acetone (generally the contained oil ); (2) soluble in hot acetone (the soft wax portion); and (3) insoluble in acetone (hard wax). The hard wax material consists of straight chain material with molecular weights of 525 to 700 daltons. The proportions of each of these will vary from well to well, and even in a given well at different times. Burger et al. (1981) found that deposits in the trans-Alaska pipeline consisted of 14 to $17 \%$ solid (wax), 86 to $83 \%$ whole oil.

Sometimes crude forms very stable, high-viscosity emulsions with water which are mistaken for paraffin problems and sometimes asphalt problems exist. McCall et al. (1984) gave a helpful test for the field determination of the nature of deposits as a guide to the operator: (1) Heat to 125 to $150^{\circ} \mathrm{F}$ : most paraffins will melt, while asphaltenes and inorganics do not; (2) place in water: Faraffins and asphaltenes float, inorganics sink; (3) place in hot xylene: paraffins and asphaltenes dissolve, inorganics do not; and (4) place in pentane or gasoline: paraffin dissolves, asphaltenes and inorganics do not.

\section{PRECIPITATION AND DEPOSITION OF PARAFFINS}

Under the conditions of temperature, pressure and crude oil composition occurring in an underground reservoir, the paraffin is in solution in the crude. As the oil flows to the surface there is generally a reduction of temperature, pressure, and the amount of dissolved gases contained in the oil. This reduction of temperature and gas breakout are factors causing reduced solubility of the paraffin in the crude. Thus, as the crude containing paraffin rises to the surface and flows to storage tanks at ambient pressure and temperature, the solubility of the paraffin may be exceeded. Deposition tends to begin at the point in the system where the temperature of the system falls below its cloud point, and continues as long is there is a further drop in the solubility of paraffin in the crude. The severity of the deposition as well as the location of the bulk of the deposition will depend on the amount of paraffin originally in the crude, the manner in which temperature and pressure of the crude are reduced, and other properties of the crude and of the paraffin.

For a paraffin problem to exist, the solid must separate from solution, and it must stick to some surface. There are three mechanisms of wax deposition: molecular diffusion, and shear deposition (Addison, 1984). The mechanism of molecular diffusion is the deposition mechanism occurring during production in which the oil temperature is well above the cloud point until the oil is comes in contact with a cold surface; at that point wax comes out of solution and adheres directly to the cold equipment. Shear deposition of precipitated wax crystals occurs after the oil has fallen below the cloud point, and the crystals are transported to the wall by the shearing of the oil at the 
surface of the tubing or flowline. These crystals will deposit on the layers formed by molecular diffusion if it occurs. Shear dispersion is the main mechanism of deposition for any situation where oil temperatures are below the cloud point. In the study of precipitation of wax from crude oil, it is an oversimplification to regard paraffin as a single entity. Thus the statement of Hunt (1962) "paraffin deposits are initiated by the precipitation of paraffin directly on or adjacent to the pipe wall and grow by the diffusion of paraffin from solution to the deposit" describes what is happening in a cold finger, but does not address the full complexity of paraffin accumulation. The deposition of paraffin by molecular diffusion can take place even when the crude is below its cloud point; that is, the mechanisms of molecular diffusion and shear deposition can occur simultaneously.

The next section treats precipitation of paraffin, followed by a critique of the most common test, and finally there is a section on accumulation of paraffin in the well or tubular goods.

\section{Deposition of Paraffins}

Many of the authors listed in the bibliography have studied the deposition of paraffin; this section will summarize their observations. For more detailed information, the reader is referred t $^{\text { : }}$ Addison (1984), Agrawal et al. (1989), Agrawal et al. (1990), Brown (1940), Bucaram (1967), Burger et al. (1981), Charles (1984), Cole and Jessen (1960), Gdanski (1984), Howell and Jessen (i956), Hunt (1962), Jessen and Howell (1958), Jorda (1966), Matloch and Newberry(1983), Mills (1932), Nathan (1955), Newberry and Barker (1985), Patton (1970), Price (1971), Reistle (1928), Reistle and Blade (1932), Shock et al. (1955), Sutton and Roberts (1974), Thomas (1988), Uren (1953), Weingarten and Euchner (1988), Won (1986), and Wright (1951).

\section{Laboratory Techniques for Evaluating Paraffin Problems}

1. Determination of the cloud point. The cloud point is the temperature at which paraffin crystals start to form. Since crude is often opaque, cloud points are often determined by measuring the viscosity as a function of temperature. The temperature at which viscosity markedly increases is taken as the cloud point. Using the viscosity criterion, a crude may have several cloud points, but it usually has a major cloud point. Since the production system has a varying temperature profile, hotter downhole and colder at the surface, wax of varying composition can deposit at different locations.

2. Determination of pourpoint and yield value. When crude oil is cooled, it becomes more viscous until a temperature is reached at which the oil does not flow when a container is 
turned horizontally. This is the pourpoint. The yield value is most often determined at the pourpoint, and is the force required to make the material flow. The pourpoint often depends on history of the oil, especially if contains resins and gums. For example, heating oil to a higher temperature at the start of the test often leads to a lower pourpoint than if the same oil is heated to a lower temperature. Determining the pourpoint after heating to the formation temperature, and heating to the temperature at which a treatment is applied may produce useful information for a field problem. Crystal modifiers are often tested with the pourpoint test; but relying on this test alone may not give a good result, as the modifier may act on materials causing the high pourpoint but not on components producing the majority of wax deposition.

3. Cold finger test. In this test, a cold finger is maintained at a temperature below the cloud point while in contact with oil which is above the cloud point. The oil is usually circulated past the cold finger. In some designs, the oil is circulated inside the cold finger, which dips into a controlled bath of lower temperature. The amount and rate of deposit are measured. The temperature selected for the cold finger is the temperature of the field equipment where deposition cccurs. If this not known, the next lower known temperature is used. However, since oil may have several cloud points, results may vary depending on the temperature of the probe; two or more probe temperatures may be needed. Products are screened by adding various concentration of dispersants.

4. Paraffin deposition test. This apparatus consists of a pump to circulate oil between a reservoir in a hot region and a loop in a cold region. After a given amount of time, the coil is removed, drained and the wax determined. Another design determines the wax buildup by measuring the pressure drop across the coil. In still another design, the oil is placed in a beaker and heated. Coolant is passed through a tube immersed in the oil, and the wax is deposited on the outside of the tubing. The results from this apparatus show much scatter, but the turn around time is short. The paraffin-deposition test is primarily to determine the quality of the oil, and how wax is deposited from it depending on the temperature of the cold zone. It is sometimes also used to determine the effectiveness of dispersing agents.

5. Hot and cold flask tests. These tests usually are conducted to determine the efficacy of chemicals in combating paraffin problems. In the hot flask test, paraffin, water (or brine) and dispersant are placed in a flask. The flask is heated until the paraffin melts. The flask is held under cold water and shaken and swirled until cool. A blank (everything but dispersant) is run. In the blank, the paraffin will ball up and stick together, whereas in the successful test the paraffin will be dispersed and resemble coffee grounds. These pieces will not stick together. The 
compound that gives the smallest particle size and reasonably clean water at a relatively small concentration is the successful candidate. The cold flask test is similar, except no heating is done.

6. API RP 42 test, visual wettability test. A rapid method of determining the wetting tendencies of surface-active agent solutions. In this method the surface-active agent is dissolved in $50 \mathrm{ml}$ of water in a bottle containing $10 \mathrm{~cm}^{3}$ of sand. The dispersion is poured into $50 \mathrm{ml}$ of oil and the ease with which.the sand disperse in each phase is observed. The sand will dispersed easily in a wetting phase, and tend to clump in a nonwetting phase. A potential candidate should be checked to ensure that if it comes in contact with the reservoir it will not change its wettability, if that is known. If not known, the agent should leave the formation water-wet.

7. Solubility and/or compatibility test. This is a visual test where two or more products (surfactants, corrosion inhibitors, scale inhibitors, brine) are placed in a screw-cap bottle, shaken well and allowed to stand for 24 hours. The contents are visually examined in front of a viewing light to ensure that all components are compatible.

Other less widely used tests for the examination of wax are: (1) a visual study to determine the color and particulate adherence qualities; (2) a microscopic study to determine the presence of water, sand and inorganics; (3) an infrared spectrum provides a semiquantitative chemical composition; (4) X-ray studies for crystal characterization; (5) pentane insolubles correspond to resins \& asphaltenes; followed by benzene insolubles which are asphaltenes; (6) an emission spectrum of the ash speciates inorganics; and (7) a solubility test where a paraffin deposit is spread evenly on a wire mesh and dipped into a solvent. A mechanical device lifts and lowers the screen at a uniform rate and the number of dips is recorded. The effectiveness is judged by the number of dips required to remove one half of the paraffin from the screen.

Gas chromatography provides compositional analysis of oil and wax. Simple paper chromatograms can provide useful information. These are carried out as follows: a drop of crude put on 2 by 3 inch blotting paper and allowed to spread to the maximum extent; then 2 to 5 drops of non-fluorescing naphtha added in the center of paper and allowed to spread and dry; the result is viewed under ultraviolet light. This method may be useful if a large enough sample base can be created and correlated with paraffin problems, and this information can be transferred to the field.

Bucaram (1967) and Reistle and Blade (1932) among cthers used microscopic examinaticn of oil after cooling below the cloud point. The shape and size of the crystals will give an indication of the expected paraffin problem. 


\section{Results of Deposition Studies}

A summary of a large number of literature reports concerning experimental studies on paraffin deposition are as follows. For a given solvent/solute combination, the most important factor in determining solubility was the temperature, with solubility increasing with increasing temperature. At a given temperature, the melting point of the paraffin was the principle factor influencing the solubility of the paraffin in a given solvent, the solubility decreasing sharply with increased melting point. For hydrocarbon solvents, the main factor which influenced solvent power was the API gravity of the solvent; solvents of higher API gravity (lower density) being superior paraffin solvents.

The effect of solution gas on the solubility of a given wax is to increase the solubility as the amount of gas in solution increases. Since the presence of light ends increases the solvent power of oil for wax, and since the escape of gas decreases the ratio of solvent to solute, a decrease in pressure below the bubble point results in lower solubility of the wax in oil. Thus pressure exerts an indirect effect: the solubility of waxes was almost independent of pressure until gas evolution occurs.

The presence of water does not have much direct effect on the precipitation of wax, since neither oil nor wax are appreciably soluble in water, but it may influence the location of wax deposits. Some wells producing almost no water had paraffin problems which disappeared when they began producing appreciable water: the higher specific heat of the water kept temperatures in the tubing string high enough to prevent the paraffin problem. The presence of water also tended to reduce the accumulation of paraffin in a water-wet system since water-wet rock have little affinity for paraffin deposits.

The presence of gums, resins, and colloidal asphaltic material in general improve wax solubility. The loss of these materials generally lowers the solubility of wax; they also act as crystal growth modifiers. When crude oil is cooled without agitation, the small wax crystals form an interlocking network that supports the liquid constituents, and finally a temperature is reached at which the oil will not flow when tipped - the pourpoint. If the oil is agitated while cooiing or after the pourpoint is reached, it becomes liquid again, but highly viscous. Upon standing, it returns to a non-flowing liquid. Heating oil to a temperature well above that at which all wax, gum, asphaltic material is soluble reduced the pourpoint quite sharply for oils containing such gums, etc. Upon standing the pourpoint reverts to the former value. For oils from which gums etc. have been removed, or which have small amounts of them the pourpoint does not respond to such heating. 
Gdanski (1984) tested 40 crudes; he found that cloud point and paraffin content were the most important factors dictating deposition potential. Viscosity vs. temperature plots allowed estimation of both paraffin cloud point and paraffin content. Pourpoint was not strongly indicative of deposition potential. Cloud point depression was a better test for choosing an inhibitor than the pourpoint for low paraffin crudes but it was not $100 \%$ accurate.

Jorda (1966) measured paraffin deposition with a cold spot paraffin tester. Other things being equal, the rate of deposit was governed by surface roughness alone.

Jessen (1958) carried out a series of deposition experiments, the conclusions of which were as follows: (1) the rate of deposition in a steel pipe varied with flow rate, reaching a maximum just prior to change from viscous to turisulent flow. (2) deposition of paraffin on various kinds of plastic pipe showed the same general dependence un flow rate as for steel pipe; however, the amount accumulated was appreciably less on plastic than on steel pipe, (3) when cooling of the oil from temperatures above the cloud point took place at the pipe wall, an increased deposit of paraffin resulted when compared with that obtained when the oil had been cooled below the cloud point prior to circulation through the pipe, (4) the rate of accumulation of paraffin on plastic pipe seemed to increase with the degree of wettability by the crude oil, (5) plastic pipe did not entirely eliminate the problem, but the rate of deposition on plastic or plastic lined pipe was substantially lower than on steel or aluminum pipe and (6) predictions as to the severity of the paraffin problem must be based not only on cloud point but also on concentration of wax in solutior.

Weingarten and Euchner (1988) performed wax crystallization experiments on live oil using a filter and measuring the pressure drop across the filter, diffusion deposition experiments, and shear deposition experiments to determine the effect of changes in oil flow rate on wax deposition, and to resolve differences between predictions and field experiences. Along with several other conclusions they pointed out that the experimental results can be used to predict conditions needed for wax deposition and the deposition rate associated with these conditions. Deposits once formed could be removed by flowing oil. The sloughing of deposits took place when shear stress was great enough; however, the onset of sloughing did not necessarily occur at the transition from laminar to turbulent flow. For a given oil, a pressure/temperature envelope that defines the conditions under which wäxes will precipitate could be determined experimentally. Wax solubility could be expressed in accordance with ideal-solution theory for paraffinic waxes in paraffin based oils. This latter work, together with the work of Won (1986), who described a method of calculating solid-liquid-vapor three-phase equilibria for hydrocarbon mixtures containing methane 
and light gases as well as very high-boiling hydrocarbons, provide a starting point for the calculation of paraffin deposition from crude oil composition.

\section{Critique of the Cold Finger and Flow Deposition Tusts}

Shock et al. (1955) expressed dissatisfaction with many of the deposition rate studies. They felt that the then current methods which often consisted mostly of running oil through tubing in cooling bath, with or without the addition of wax from surface piping, often failed to give helpful data with regard to real field behavior.Over the next 30 years, there has been little change in the nature of these tests; most deposition studies still rely heavily on the cold finger and fluid flow tests.

Some of the limitations of the cold finger and cold tube tests are as follows:

1. In the basic cold finger test, the oil is above its cloud point. It is brought into contact with a surface which is kept below the cloud point. This simulates the situation in which the oil has never fallen below the cloud point, or has been reheated sufficiently to redissolve the paraffin. The cold finger test does not simulate the shear deposition mechanism. It is seldom possible to apply the cold finger test to oil which has been cooled below the cloud point.

2. If the well produces emulsion or water, the cold finger test does not model it well. When running a cold finger test, the crude must be carefully separated from water or emulsion to get the oil water free. Thus the test is not representative of the conditions in the well.

3. The cold finger test is limited in its utility for selection of chemical additives. Because clean oil is used, and the deposits are formed by molecular dispersion, an additive which might be the best in handling deposition by shear dispersion, but which depends on the water in the well for its effectiveness would fail the cold finger screening test.

4. If an accumulation of paraffin falls off the cold finger before weighing, it can give faise results.

The problems of the cold finger and flow deposition tests still exist. Hiebert (1991) remarked that there is a great need of a reproducible test for paraffin deposition. He also mentioned that there is a great deal of trouble in obtaining representative samples, especially oil samples. 


\section{Representative Samples}

For meaningful results, care must be taken in securing samples of the paraffin and of the crude oil. Since various kinds of paraffin deposit in different locations, care must be taken that the paraffin sample and the oil sample are representative of the problem. Paraffin and oil in the well head, in the tubing, and on sucker rods may be different, and a treatment based on one of these may not help the others. There may te a specific site in which a chemical treatment of paraffin is more beneficial than a treatment ay a different site, so the treatment must handle that site. Paraffin composition differs in different parts of the field, in different parts of the well and in all of these at different times. The composition of oil in contact with the paraffin will vary in a similar manner. Obtaining representative samples of oil and paraffin is not a trivial matter.

\section{Accumulation of Paraffin}

Brown (1940) and Reistle and Blade (1932) among others emphasized that precipitation of paraffin from a fluid did not necessarily lead to the accumulation of paraffin, because, often, the paraffin crystals remained in and were produced with the crude. Once supersaturation occurs, conditions favoring accumulations of paraffin are: (1) dead fluid spaces; (2) rough places in pipe, such as grooves; (3) cold spots, such as gas-lift foot valves; (4) alternate coating and draining of pipe surfaces, as is normal in surging wells; (5) oil produced as a mist, covering the pipe with a film, as is experienced in high gas-oil ratio wells; (6) movement of oil at slow rates approaching streamline flow, (as in stripper wells) especially if the pipe is much cooler than the oil; in this case the paraffin may be precipitated directly on the pipe, and thus adhere to it; and (7) the presence of foreign particles to provide nuclei for paraffin formation.

Paraffin accumulates in five locations in oil fields, they are:

1. Paraffin on the sand face or perforated liners. This is hard to detect, for the production decline is often mistaken for a normal decline. This condition is often present in old wells where a marked reduction in pressure has released light ends. Vacuum pumps may aggravate the situation.

2. Paraffins in the tubing of flowing wells. The effects of deposit in tubing are abnormal production declines, complete killing of wells, and increased difficulty in running subsurface instruments. It is caused by the cooling from gas expansion and conduction of heat to the surrounding formation. The tendency of flowing wells to surge is one of the prime reasons for paraffin accumulation. 
3. Paraffins in pumps, sucker rods, tubing and wellhead of pumping wells. These deposits are caused by heat loss to wellbores and loss of volatile components. They produce increased wear on pumping equipment, increased power consumption, added difficulty in pulling rods, and failure of rods to fall; they also lead to production declines, rod failure and split tubing.

4. Paraffin in flow lines. Caused by low temperatures in the flow lines. The effects are unnatural production-rate declines in both flowing and pumping wells, stuffing box failures, extra power consumption, and increased wear on pumping equipment.

5. Paraffin in stock tanks. For a long time it was not economical to recover the waxy ends for pipeline sale. Bottoms were used as lease road-surfacing material, or burnt in pits. Currently the expense of treating bottoms and the resultant high paraffin crude lead to lower profits.

\section{OPERATION PROCEDURES TO PREVENT PARAFFIN ACCUMULATION}

There are several operating procedures which minimize the deposition of paraffin in the sand and in the tubing. Reistle and Blade (1932) recommended "the oil needs to be produced with minimum of gas and maintaining a steady flow of oil. This will help prevent precipitation of paraffin, or at least to tend to eliminate the conditions which cause precipitated paraffin from becoming attached to the pipe. These conditions can often be regulated by the use of proper size tubing, choke, a back pressure regulator, or a combination of these. The choice of the proper combination of conditions may take considerable experimer... tion. Even after conditions are established, they will usually have to be aitered from time to time as the rate of gas and oil production changes. If possible, the tubing should be full of oil at all times, not allowing the oil level to fall between times of production if production is intermittent. In one stripper well, the sand was suspected of having paraffin. It was washed well with gasoline, and the pump raised to the top of the sana to maintain the fluid level near the top of the sand. Within a short time production was more than it had been for several years. By maintaining the pressure and fluid level constant the maximum amount of oil can be produced with the minimum of paraffin." These recommendations remain valid today.

Wells with high gas-to-oil ratios (GOR), wells flowing intermittently, and wells on gas lift tend to paraffin up. In the case of high GOR, keeping a backpressure on the well (if it does not prevent the well from flowing) helps to lessen paraffin problems. Gas dissolved in crude oil easily forms a supersaturated solution; when the fluid is agitated, the gas comes out of solution. If the pumping speed is greater than that required to lift the available oil, some gas is churned through the 
pump. This agitation tends to cause gas to come out of solution; the loss of light ends and the cooling of the gas on expansion lead to paraffin deposition. When compressed air or gas is used to keep oil flowing, a definite cooling results from the expansion of the gas while lifting the oil. Care should be exercised that the amount and pressure of the gas be kept as low as possible to minimize local cooling.

Paraffin problems can be prevented by maintaining the temperature in the well above the pourpoint of the oil. Using smaller tubing to increase the flow rate is sometimes all that is needed; this leads to higher wellhead temperatures as well as providing turbulent flow in the tube which tends to remove precipitated paraffin and keep them dispersed in the oil. Insulating the tubing has been helpful in many wells (Davis, 1982.). Free convection in the annulus has been shown to be a significant heat-loss mechanism. Ashford et al. (1989) reported that free convection in the annulus has been shown to be a significant heat-loss mechanism. Application of gelled packer fluid in this annular space stops annular convection so that the produced fluids are hot enough to prevent paraffin problem. The temperature increases from gelled packer fluid application alone eliminated paraffin problems previously controlled with hot oil treatments. Prior to this application, chemical inhibition treatments were unsuccessful (partly because they were applied too high in the tubing).

Electrical heating is sometimes used to keep the temperature sufficiently high (Enhanced Recovery Week, 1988, Electrothermic). Yukl (1988) and the American Oil and Gas Reporter (1989) proposed heating of a tubing string by turning the tubing string itself into the heating element

Keeping ali tubing very smooth is helpful in preventing paraffin deposition. Other things being equal, the rate of deposition is governed by surface roughness alone (Jorda, 1966). Most smooth, non-paraffinic plastics lessen deposition, but these plastics need to be flexible and highly polar if the stream contains abrasive materials. Operating the well so that surfaces remain water wet will lessen paraffin accumulations.

Chemical agents are most often used for prevention rather than as clean up agents. Rahimi (1991) remarked that paraffin problems can be lessened by feeding dispersing agents into the production stream. Charles (1984) points out that the benefits of a simple, widely applicable paraffin inhibition treatment include: less time spent in designing methods of well treatment and maintenance; treatment and workover intervals can be extended; and fewer interruptions of well production. The inhibition mechanism is that it makes all surfaces water wet. 
Simon and Poynter (1968) and Beyer and Osborne (1969) suggested the use of a down-hole emulsification process to improve productivity and operating efficiency of oil wells that produce viscous crudes. The process involved adding a surface active agent to the wellbore to convert high viscosity oil to low viscosity oil-in-water emulsions. Improved pump efficiency, faster rod drop rate, and a lower flow line pressure results. Benefits also include a lessening of paraffin problems

An inhibition process was described by Charles (1984) and by Settineri (1984) could be used to remove paraffin as well as to prevent new buildup. To apply the treatment, a well must be dried and purged with nitrogen. Gaseous sulfur trioxide is applied down the tubing and the well is returned io flow. Water deactivates the chemical. After treatment, a well may need a 10-30\% water cut to stay water wet.

The use of these and other chemical agents will be treated in more detail in the section on chemicals.

Sutton and Roberts (1974) warn that cold fracturing fluids can cause a paraffin problem in the formation. Once paraffin is deposited, it is very difficult to redissolve unless the temperature goes above the melting point. The operator needs to calculate cooling and thermal balance associated with the fracture treatment.

If the operation conditions are favorable for paraffin deposition, it is prudent to perform laboratory tests to evaluate this potential and to design preventive and maintenance to prevent production disruption because of paraffin deposition. Santamaria et al. (1991) described a program of laboratory tests which include hydrocarbon analysis by high performance liquid chromatography and gas chromatography, cloud point and pourpoint measurements, and coldfinger and paraffin deposition tests. Chemical screening were performed using the cold-finger and paraffin deposition tests with addition of chemicals. It was found that chemical alone was not capable of totally preventing paraffin deposition. A program of combining chemical injection at the wellhead, flowline insulation and pipeline pigging was selected for implementation in the field. As a results of the chemical treatment paraffin deposition was minimal and easily removed by pigging.

\section{Crystal Modifiers}

The terms crystal modifiers, inhibitors, flow improvers, and pourpoint depressants seem to be used synonymously. McCall et al. (1984) define inhibitors as "generally consisting of high molecular weight copolymers of ethylene and vinyl acetate, which have enough structural similarity to paraffin to enter into the paraffin crystallization process. The molecular weight of inhibitor 
compounds ranges from 1,500 to 100,000 daltons. Paraffin inhibitors function by modifying or blocking the formation of large paraffin crystals." Although McCall stated that reduction of pourpoint by an additive can be used as a measure of its effectiveness, it is not always a good indicator (Gdanski, 1984). As early as 1932, Reistle and Blade mentioned the field use of crystal modifiers in a controlled-release matrix.

According to Price (1971), when a waxy fluid is cooled below its cloud point, wax crystals form and begin to agglomerate. As the temperature is further reduced, crystal agglomeration reaches the point at which a ivose gel structure is formed. This gel structure can be broken down by the action of shear, but tends to reform on standing. The wax crystal habit is dependent on the crude oil, rate of cooling and degree of agitation during cooling, among other variables. Wax crystal modifiers, when added at a concentration of 0.002 to $0.5 \%$, have been found to modify crystal habit, size and crystal/crystal adhesion. The changes in crystal habit and size and the reduction of the tendency of crystals to adhere to each other combine to reduce the temperature at which a gel structure is built up during the cooling of a waxy fluid. It should be noted that, in general, wax crystal modification by additives does not significantly alter the amount of wax precipitated or the temperature range over which precipitation occurs. Four proposed mechanisms by which wax crystal modifiers act are: (1) nucleation of wax crystal growth so that increased numbers of small crystals are formed; (2) surface adsorption to reduce crystal/crystal adhesion; and (3) co-crystallization with the growing wax crystal leading to changes in crystal habit and reduction in crystal/crystal inter-growth. This latter is favored by the experience and laboratory tests of Price, using a type of cold finger to test wax deposition and its control.

Gavlin et al. (1953) studied the pourpoint depression of lubricating oils. Their work supported the theory that pourpoint depressants work via adsurption on a growing wax crystal face.

Bucaram (1967) found that some crystal modifiers prevent nucleation; some coat the particles so they don't agglomerate. Polyethylenes were found to be very good crystal inhibitors. He used microscopic examination of the oil after cooling below cloud point, examining crude fractions as well as whole crude. He found that crystal modifiers are selective. Polyethylene, 20,000 daltons with low crystallinity performed well in crude oil.

Crystal modifiers need to be continuously present in the production stream to be of highest value. Some application methods include batch treatments such as running down the annulus, addition to frac fluids, and squeeze applications into the formation, sometimes being followed by 
squeezing a chemical that will precipitate the modifier, thus prolonging the treatment. Continuous treatments include bleeding into the production stream using a small tube added for this purpose (however, operators are reluctant to run small-diameter tubing which needs to be attached to production tubing, since this may require an additional expense in pulling and running tubing, as well as being inconvenient in servicing the well), a side stream flush, and the use of a controlled release pellet. Bilderback et al. (1969) used crystal modifiers with success, but noted that they need to be continuously added to the recovery stream. Matloch and Newberry (1983) concluded that the best additives lower pourpoint about $20^{\circ} \mathrm{C}$. These additives change the mnlecular weight distribution of wax and make it less hard. They do not cure the problem, but can be economic in that they reduce the cost of other treatments such as heat. Newberry (1984) stated that vinyl acetate, $\mathrm{C}_{18}-\mathrm{C}_{22}$ methacrylates, and olefin/maleic anhydride esters were used as inhibitors; they slow the deposition but do not end it. Svetgoff (1984) and Wagner (1989) reported success in combating paraffins using inhibitors. Woo et al. (1984) noted that crystal modifiers are highly selective. They used a blend of crystal modifiers in a controlled release pellet, measuring the time required to dissolve the pellet. Pellets developed in this research were applied to two wells. Results were encouraging; problems have been absent for a year since the treatment. Haynes and Lederman (1986) applied an inhibitor by squeeze, followed by squeezing a chemical which precipitated it. The precipitate releases the chemical slowly over a long period, prolonging the life of the treatment. Garbis et al. (1984) recommend the addition of inhibitor to frac treatments if they are used; the inhibitor will produce for 4 to 6 months. By then the operator should have decided what long term treatment to use.

\section{Crystal Modifiers Used in Pipelines}

The use of inhibitors or pourpoint depressants is very common in the transport of waxy crude. The work of Price (1971) was undertaken because of the difficulty in transporting waxy African crudes through continental European pipelines. Uhde and Kopp (1971) listed methods of transporting waxy crudes: (1) as an emulsion; (2) dilution with lighter oils; (3) preheating with subsequent heating in the line; (4) preheating and insulation; (5) special heating/cooling treatment; (6) injecting a water layer between the pipe wall and the crude; and (7) wax crystal modifiers. The method to be used will depend on economics. However, the treatment for a particular problem needs to provide for the possibility of the interruption of flow for a time, and to guard against the crude congealing in the pipeline during such an interruption. Brod et al. (1971) used an unnamed coded additive to enable the pipeline transport of waxy crude. 
Mendell and Jessen (1972) studied the flow characteristics of crude oil at temperatures below the cloud point, exarained the effect of various additives on these flow characteristics, and correlated any changes in flow characteristics with depositional tendency. The correlation was not entirely successful.

Sifferman (1978) investigated the flow properties of waxy crudes. Because of viscosity, gel strength and/or high pourpoint, many waxy crudes were difficult to produce and transport at ambient conditions. He determined viscosity, gel strength (yield value) and pourpoint data with and without flow improvers based on maleic anhydride, polyethylene, or polyacrylate. The additives were very selective; it was necessary to use a trial-and-error method in selecting additives. Chemical additives (flow improvers and emulsifiers) showed promising results. Wax crystal modifiers reduced viscosity, gel strength and pour points.

van Engelar et al. (1981) tested additives for effect on yield values, pour points, and viscosity, using a $6 \mathrm{~mm}$ model pipeline. After an additive was selected and used at about $350 \mathrm{ppm}$ the pipeline was shut down for 10 days, and restarted without a problem. Slater and Davis (1986) used a pourpoint depressant to solve their pipeline problems. Selection was made using laboratory studies of pourpoint and yield values. During the first year of operation they found that the required dosage rate was lower than the laboratory design value, and it has been possible to devise a management plan which minimizes startup difficulties. This is a very complete paper outlining procedures used in selecting and monitoring a chemical additive in conjunction with the pipeline design that resulted in essentially a trouble-free system.

\section{METHODS OF TREATING PARAFFIN ACCUMULATIONS}

If paraffin has been allowed to accumulate in a well to such an extent that production is curtailed, any of several different methods may be employed in removing it and restoring the well's productivity. These methods are grouped into three main categories: mechanical, thermal, and chemical; there are, of course, combinations of these methods.

\section{Mechanical Methods}

Reistle and Blade (1932) showed an impressive list of tools used to scrape paraffin from the tubing. Included are "standard tools" consisting of socket, jars, stem and bit. For flowing wells, the paraffin cutter or paraffin knife was often used. The paraffin hook was a positive method of removing large quantities of paraffin from a well. It often consisted of a heavy disk which slipped 
into a neutral position while the tool was lowered, and slipped into an active position when the tool was withdrawn.

Brown (1940) recommended mainly mechanical methods of paraffin removal. For flowing wells, treatment mainly was by scrapers, either wireline or automatic scrapers was used. For pumping wells scrapers were used. Wright (1951) mentioned that pigs, the paraffin knife, paraffin hook, corkscrew, porcupine, and swab were in general use. Some operators pulled tubing and built a fire under it to remove paraffin.

Uren (1953) stated that various forms of mechanical rotary reaming devices, designed to expand against the walls of the well and scrape off the paraffin had been developed and found to be useful. Some of these were effective in wells of moderate diameter, but are scarcely adaptable in large shot cavities in which the walls are several feet from the well axis.

Tuttle (1983) reported on a field in South Louisiana. The wellhead was too hot to touch, but surface pipes had paraffin deposition. The most cost effective method was cutting and pigging the surface pipes.

The early authors mainly recommended mechanical methods of paraffin removal. Mechanical methods (Woo et al., 1984) are still in use, and in many cases, the most cost effective way to deal with the paraffin problem. Many of the more recent authors mentioned mechanical methods, but provided very little details of the practice.

\section{Thermal Methods}

\section{Hot Oil}

The most common thermal method of dealing with paraffin deposits has been the use of hot oiling. Hot oiling is the process of using heat to meii paraffin deposits for removal from the well. A truck picks up a load of oil from a lease tank, heats the oil to 150 to $300^{\circ} \mathrm{F}$ and pumps it into the well. Hot oiling is applied either directly down the tubing, or in the annular space, with the latter being more common. Hot oiling down the annulus is essentially a heat transfer process. As hot oil is moves down the annulus, the tubing becomes hot enough to melt the wax. As the depth of deposits in tubing increases, the amount of oil and often its temperature must increase in order to treat these deeper deposits. The oil falls to the bottom of the well, where it is eventually produced back to the surface. Porter (1990) did a survey of several companies in Oklahoma and Texas and reported the cost of hot oiling to be $\$ 150$ to $\$ 300$ per well per application. 
Hot oiling on a regular basis is recommended by several authors, and several refinements have been developed. The purpose of these innovations is to prevent contact of the hot oil with the formation. Spitzer (1987) patented an annular plug which fits on the string. It slows the passage $r f$ hot oil down the annulus so that heat is more efficiently transferred to the tubing string. Whitley and Poque (1985) have patented a valve which enables fluids to be returned to the surface through the annulus between the casing and the string. Billingsley (1963) described a system in which the sucker rod is hollow to a depth below the paraffin zone, and solid below that point. Hot $\left(325^{\circ} \mathrm{F}\right)$ oil is periodically circulated down hollow rods below the paraffin deposit, and up the annular space between rods and tubing.

Hunt (1984) has patented a process similar to hot oiling. Produced oil was heated to reduce its viscosity; he referred to this as visbroken produced crude. This hot visbroken material was pumped down into the formation, then recovered. It reduced crude viscosity in the vicinity of the wellbore and cleaned paraffin from the formation.

\section{Hot Oil Critique}

The problems associated with hot oiling have been pointed out by Barker et al. (1984), Brock (1984), Newberry and Barker (1985), Barker (1989), and Wagner (1989) among others. Hot oiling systematically concentrates the higher molecular weight paraffins in the wellbore and even reintroduces them into the formation. Hot oiling cycles tend to build up paraffins at the face or even within the formation, especially in wells having low downhole pressure.

The hot-oil process has several mechanisms which can lead to formation damage. The fact that hot oiling is being used indicates that the oil contains paraffins. The source oil for hot oiling is often taken from the bottom of the sales tank. This oil has a higher concentration of paraffins than the formation oil because of the loss of gas, loss of light ends, and the accumulation of precipitated paraffins. During the heating process, more light ends are driven off, increasing the cloud point of this oil even further. When this oil is pumped into the well, the worst oil on the lease is falling to the bottom of the well, cooling as it goes, aggravating the paraffin problem. Straub (1989) and Cheng (1991) did a field study of the hot oiling process. They measured the downhole temperature and pressure of wells having a depth of 4500-6000 feet. The results showed that the bottomhole temperature fell because the "hot oil" reaching the bottom had cooled below the producing formation temperature due to heat loss to the surrounding. The bottom hole pressure increased enough to squeeze some of this oil back into the formation. Thus hot oiling can lead to systematically recycling paraffins back into the formation. 
If hot oil treatment is the only alternative, the operator should use the best oil available, namely oil from tanks without asphaltene, paraffin or solids problems. Use the top oil in the tank, not the bottom. Treat oil with chemicals or added solvents. Only high boiling solvents such as xylene, diesel and kerosine should be used.

Rahimi (1991) remarked "A rule of thumb is that one needs to heat the wax deposits about $100^{\circ} \mathrm{F}$ above their accumulation temperature in order to remove them Once paraffin deposition occurs, you have to pull the tubing and mechanically scrape out the paraffin. Anything else runs the danger of losing the well."

\section{Alternatives to Hot Oil}

Brock (1984) lists several alternatives to hot oiling, such as hot diesel, hot kerosine, or hot xylene. These are more expensive than hot oiling, but have less tendency to deposit paraffin in the formation. Hot water is often useful since it has a greater heat capacity than hot oil, although in some cases water contact changes the wax from a soft to a very heavy, hard material similar to canning wax. Green (1988) advocated the use of hot air heater to melt wax.

Hicks (1990) recommended the use of hot water with a nonionic surfactant applied down the annulus to treat paraffy in the tubing. Paraffin in surface lines was treated with hot oil with either a paraffin solvent or a dispersing agent. He found that periodic injection of dispersants down the annulus provided little help. Coppel (1991) reported that the hot oil process had been applied in a field of very high paraffin content near Vernal, Utah. He ran laboratory tests to compare hot oil, oil with additives (their own products and products from a variety of manufacturers), hot water, dispersants, microbial and solvents. The conclusion was that the preferred technique is the use of hot water without additives.

Uren (1953) reported that other commonly used methods of removing paraffin involve direct application of heat with the purpose of melting the wax so that it flows under the influence of formation pressure from the reservoir rock into the wells and out through the tubing. In addition to the use of hot solvents, superheated steam is frequently used and is quite effective if it can be forced down to the horizon of reservoir rock without serious loss of temperature. Circulation must be established in order that a continuous supply of live steam may flow over the rock walls exposed in the well. This may be accomplished by forcing the steam down to the bottom of the well through tubing, allowing it to return to the surface between the the tubing and the casing. If a well is being pumped, a convenient arrangement provides a string of tubing telescoped over the tubing through which oil is lifted to the surface. Steam is introduced at the surface between the 
two tubing strings and returns to the surface between the outer tubing and the well casing. This steam serves to melt paraffin deposited on the sucker rods and oil tubing, as well as wax deposited the near wellbore. Care should be taken that no great steam pressure be developed within the well; otherwise the melted paraffin may be driven further into the formation.

Other methods of developing heat for use in melting paraffin in wells involve the use of chemicals (Uren, 1953; Wright, 1951). Calcium carbide introduced into a well with water generates heat and acetylene gas. A mixture of caustic soda and nıtallic aluminum filings is a patented process for generating heat (Reistle and Blade, 1932). A mixture of sodium peroxide and water has been used on a very limited scale. Such chemical methods of generating heat are expensive, could be environmentally unacceptable and would be advantageous only in special cases. Woo (1984) mentions heat producing chemical reactions such as magnesium bars with $\mathrm{HCl}$. Ashton et al. (1986) describe a thermal stimulation process using chemical to generate heat downhole and also produces nitrogen gas.

The use of fire or direct burning in the well had also been proposed. (Mills, 1923 ; Uren, 1953)

Many cil producers have made a practice of combating wax accumulations in wells with the aid of explosives (squib shells containing 5 to 10 qt. of nitroglycerine). (Uren, 1953). This is an effective method of removing such accumulations; it functions not only by the violent disintegrating effect of the explosive on the wells, but also by the effect of heat generated by the explosive in melting the paraffin.

Using electricity for heating wells is a practice which has been used for some time. It is not more widely used because of the cost. Uren (1953) mentions that electric heating devices lowered into the well on a two-wire insulated and armored cable have been used to melt paraffin. A serious induction loss may result unless a non-magnetic armor is used on the cable. Yukl (1988), Enhanced Recovery Week (1988), and the American Cil and Gas Reporter (1989) describe systems in which the tubing string itself becomes the heating element. However, the annular region must be kept free of electrically conducting fluids. Economy is improved by cycling the power on and off.

Stine (1984) patented a novel method for treating high viscosity oil near the well bore, as well as paraffin in the formation. In this method, called in-situ hydrocracking, the formation is heated with a fire flood to $500^{\circ}-900^{\circ} \mathrm{F}$; hydrogen at $200-5000$ psi is forced into the formation, 
and the well is allowed to soak for 48 hours. The resultant hydrocrucked petroleum is recovered as the well is returned to production.

\section{Chemical Methods}

The major types of chemicals available for paraffin treatment are: 1 . Solvents, which act to dissolve paraffin from its deposits. 2. Paraffin inhibitors, sometimes called crystal modifiers, are used to alter paraffin crystal growth. They are usually polymeric materials, and there is usually no easy way to introduce them into the formation except during fracturing or other squeeze treatments. These materials tend to be very specific, and must be tailored for each well. 3. Paraffin dispersants. These do not prevent the precipitation of paraffin, but coat the particles, reducing their tendency to stick to each other or to other surfaces. 4. Surfactants, which act to solubilize the wax, usually into an aqueous phase. Products of types 2, 3 and 4 generally tend to be quite specific to a particular paraffin or oil; they are selected by taking samples and testing each of a variety of products until the best one is found. Testing labs are experienced which helps to narrow the range of products, but the testing of 30 to 50 fommulations is routine. The tests used have been described above, in the section "Deposition."

Addison (1984) notes that chemical treating programs allow the operator to implement very flexible paraffin control methods. Thus the operator can design stop gap measures, maintenance or production stimulation plans as the situation requires. Stop gap, or as-needed, measures are the most cost effective method of paraffin control on easily accessed wells that have problems once a year or so. In this case, the use of solvents or dispersants avoids the danger of damage to the well that hot oil may cause. For a well not easily accessed, such as during the winter, a maintenance program may be called for, since the down time caused by the paraffin problem may be avoided. In a flowing well with no capillary tubing strings for injecting chemical downhole, chemical inhibition is not possible unless solids are added to frac fluids, or solids are put into the tubing and allowed to fall to the bottom of the well. If there are downhole injection facilities, the use of inhibitors would probably be the method of choice.

\section{Solvent}

The use of solvents in treating paraffin problems began early and was widespread. Solvents should be used hot if at all possible, since elevated temperature increases wax solubility and increases the rate of wax removal. One of the very best solvents is carbon disulfide, but because 
of its poisonous nature, high flammability and cost, it is not used in the field. It is used in the laboratory as the standard against which other solvents are compared.

Amiong early references to the use of solvents were Mills (1923); also Reistia and Blade (1932) who listed gasoline and kerosine as useful solvents. Wright (1953) listed naphtha, benzene, casing head gasoline, and commercial solvents as being suitable for use in the field. A satisfactory method of application, if a regular schedule is followed, is for the pumper to loosen the packing box and pour the solvent into the tubing. After letting it wcrk for a period of time, the well is pumped off. Solvents must be used in a timely manner. They are not effective if the wax accumulation is thick, unless some mechanical agitation is present. Wright also pointed out that salt deposition in the tubing formed a rough surface to which the paraffin could adhere. Often, running fresh water in addition to solvent loosens both sait and paraffin, allowing the latter to be puniped from the well.

Uren (1953) noted that if wax has been allowed to accumulate in a well to such an extent that production is curtailed, any of several different methods may be employed in removing it and restoring the well's productivity. A common method involves the introduction of wax-solvents, such as benzene, gasoline and heavier distillates. Better resuits have been secured when the solvent has been preheated to such an extent that it melts the wax. Though the effeciveness of the solvent is increased by heating when used in this was, its primary function is to serve as a carier for heat. The solvent may be run into the well through tubing or between the well casing and tubing, or it may be poured irto the open casing of a well or lowered in a dump bailer. The dumpbailer is especially useful in introducing solvents with little temperature loss. Hot solvent should be promptly bailed or pumped out of the well to prevent the molten wax from soiidifying again in the well as it cools.

Woo et al. (1984) mentioned that chlorinated hydrocartons are good because their high gravity gets them to the wax deposits. The American. Oil \& Gas Reporter (1989) describes a chemical solvent which is a combination of aromatics, surfactants, and homogenizers; it is supposed to remove both wax and salt deposits.

Thierheimer (1990) has patented a mixture of aromatic and aliphatic hydrocarbon, with or without surfactant, for use as a paraffin solvent. He cited tield examples among which was the treatment of a $250 \mathrm{bbl}$ tark with $15 \mathrm{in}$. residues in the brttom. It was treated with 5 gal 50/50 naphtha/toluene, filled with oil and agitated. All the residues dissolved. 
Straub et al. (1989) undertook a study of the use of solvent for paraffin removal. They were prompted to undertake these experiments by the poor performance of the hot oiling processes, especially the fact that the bottom hole temperature was lowered by the usual hot oiling procedure. They included paraffins from many areas, and varied temperature, solvent type and time. The solvents tested included xylene, kerosine, diesel, condensate, oil, toluene, gasoline and mixtures of the products. Xylene and xylene mixtures performed the best; the performance of toluene was comparable, but its higher cost, and lower flashpoint weighed against it.

Straub also found that solvent action on paraffin is mainly dependent on the solvent type, paraffin characteristics and temperature. The effect of circulation of solvent past the deposit is important. For certain paraffins, the solubility in xylene is a smooth function of temperature, while for others, usually those with longer chain length, there seems to be a threshold temperature above which there was a large jump in the speed of removal. He showed that commercial paraffin solvents with water soluble dispersants showed various responses. The solvents with a large fraction of xylene performed well. The water carried dispersants were slower acting and required sufficient temperature for best results.

The application of solvents, like the mechanical removal of paraffin, does not prevent the further deposition of paraffin. Sometimes periodical removal of paraffin is the most economical method of treatment, and sometimes the present accumulation of paraffin needs to be removed, and a program of additives undertaken to retard future buildup of paraffin.

\section{Dispersants}

Paraffin dispersants are compounds that have the ability to coat small particles of paraffin, decreasing their tendency to agglomerate or to cling to other surfaces such as pipes and rods (McCall et al. 1984). These products are formulated so that one end is attracted to the paraffin crystals, and the other end is soluble in either oil or water, depending on which phase is to receive the dispersed paraffin. Ideally, they should possess enough penetrating power to break up accumulated masses of paraffin; but in practice, the dispersants usually need the assistance of heat or solvents to remove accumulations, or are applied after well cleanout.

Dispersing agents can be applied along with descaling materials in squeeze processes, or they can be applied in a batch mode down the well bore; or they can be bled into the production stream through small tubing added for this purpose. Going (1989) describes equipment by which various chemicals can be applied to the interior of tubing while maintaining production. 
In one example, McClaflin and Whitfill (1984) tested dispersants and selected two: one was water soluble and one $w$ as oil soluble. The oil soluble dispersant was used in wells with a very high oil cut, while the water soluble one was used in wells with a high water cut. They were used in batch treatments in the wells, along with corrosion inhibitors. Application was about every two weeks. They did not eliminate the need for hot oiling, but cut down the frequency of it. They reported a savings of $\$ 10,000$ per year on three wells.

Svetgoff (1984) reported on the successful use of dispersants. Newberry and Barker (1985) squeezed a dispersant and after a week shut in were able to remove paraffin from formation and restore a well.

Brock (1989) described the selection of a dispersant based on wax properties and laboratory experiments for the treatment of two wells. It was not stated whether the field test followed a hot solvent treatment. One drum of test material was mixed with $25 \mathrm{bbl}$ of lease crude and flushed with $150 \mathrm{bbl}$ of produced water down the annulus. The well was closed in for 24 hours to allow the chemical to soak into the formation. As a result, neither well was hot oiled for over a year. An average savings of $\$ 3: 0$ per well per dispersant treatment was reported.

Hicks (1990) re :ommended the use of hot water with a nonionic surfactant in the annulus while treating surface lines with hot oil containing either a paraffin solvent or a dispersing agent. Periodic application of dispersants down the annulus provided little help.

\section{Surfactants}

In addition to chemicals specifically designed as dispersants, surfactants are used to solubilize oils and paraffins in cleaning wells and tubing; and they are used to form emulsions.

Some surfactant formulations can be used for removing as well as assisting in the prevention of deposits (Newberry 1984). Detergents are used with hot water in cleanup processes; they should be selected so that tubing and formation is left in a water-wet state (McCall, 1984). The water-wet condition promotes better production of oil and lessens the chance of further deposition of paraffins. Hicks (1990) recommended the use of hot water with a nonionic surfactant to be applied down the annulus to remove paraffin deposits; for surface lines, he recommended hot oil with either a paraffin solvent or a dispersing agent. 
The use of surfactants for the emulsification of heavy, waxy crude and of paraffins is described by Beyer and Osborne (1969), McAuliffe et al. (1968, 1969), Marsden and Raghavan (1973), Sifferman (1978), Simon and Poynter (1968), and Uhde and Kopp (1971).

For production of waxy crude as an oil-in-water emulsion, aqueous solutions of surfactants are added either continuously or intermittently to the tubing-sasing annulus of the production wells. The kinetic energy of the falling surfactant solution, the mixing action of the pump, and turbulence caused by gas liberation help to form the emulsion. Nonionic surfactants are often chosen, since they are effective in brines, form less viscous emulsions which are easier to break in the heatertreater, and they do not introduce inorganic residues which lead to refinery problems. They are chemically stable at resi voir temperatures, non-corrosive, and non-toxic. These $\mathrm{O} / \mathrm{W}$ emulsions have quite low viscosities, often much lower than the oil, and are effective in the production of waxy and heavy crude oils. Laboratory tests are used to determine the concentration and the specific surfactant, taking into account the WOR of the producing well. Typical concentrations are $0.1 \mathrm{lb}$ surfactant per bbl oil for emulsions containing 50 to $70 \%$ oil. If the oil contains saponifiable materials, alkali may be used rather than surfactant.

Emulsification results in production increases because of several factors. The lower emulsion viscosity leads to greater pump efficiency and better rod dropping rates, as well as lower pressures in the gathering lines. Added benefits are that water in the emulsion wets the steel surfaces with a water film which reduces the adherence of oil and wax. This improves the well operation and reduces the need to periodically remove wax deposits by hot-oiling or other means. Forming $\mathrm{O} / \mathrm{W}$ emulsions in the wellbore benefits thermal huff-and-puff treatments, lengthening the time between steam injections (Simon and Poynter, 1968) and also help wells that tend to produce wax (Beyer and Osborne 1969). There is an upper limit of velocity in the pipes as too much turbulence tends to invert the emulsion, and $\mathrm{W} / \mathrm{O}$ emulsions have very high viscosities. If possible, the $\mathrm{O} / \mathrm{W}$ emulsion should be sent immediately through the pipeline rather than storing it.

Beyer and Osborne (1969) reported a field test with surfactant involving six wells producing a paraffinic crude with a pourpoint of $105^{\circ} \mathrm{F}$ and $16 \%$ wax content. Wax deposition was significantly reduced resulting in higher production and $44 \%$ fewer hot-oil jobs. Pump-rod load was reduced $20 \%$; pumping horsepower was reduced $13 \%$; and the flow line pressure dropped by $30 \%$. The savings in electric power paid for the cost of the surfactant. Simon and Poynter (1968) reported similar results at Huntington Beach, $11^{\circ} \mathrm{API}, 30,000 \mathrm{cP}$ at $80^{\circ} \mathrm{F}$, WOR 1; and at Kern River, $11^{\circ} \mathrm{API}, 42,000 \mathrm{cP}$ at a wellhead temperature of $80^{\circ} \mathrm{F}$, WOR 3; in both cases savings in 
electric power paid for the surfactant, in addition to the value of the increased rate of recovery. The surfactant use produced no adverse effects.

\section{Conclusion to Chemical Treatments}

Chemical treating programs allow the operator to implement very flexible paraffin control methods. Thus the operator can design stop gap measures, maintenance or production stimulation plans as the situation requires. In this case, the use of solvents or dispersants avoids the danger of well damage that hot oil may cause. For a well not easily accessed, such as during the winter, a maintenance program may be called for, since the down time caused by the paraffin problem may be avoided. In a flowing well with no capillary tubing strings for injecting chemical downhole, chemical inhibition is not possible unless solids are added to frac fluids, or solids are put into the tubing and allowed to fall to the bottom of the well. If there are downhole injection facilities, inhibitors would probably be the choice.

\section{Microbial Methods}

Oxygen-utilizing microbes are usually used in microbial method of wellbore cleanup. The paraffins are metabolized by the microbes are oxidized to alcohols, aldehydes and carboxylic acids In addition to metabolizing parraffinic hydrocarbons, microorganisms may produce compounds that emulsify paraffin deposits and improve fluid flow (Bishop and Woodward, 1990). The American Gas \& Oil Reporter (1989) reported that Kiseki Technology claimed the use of microbial treatments to refine waxy paraffins into production fluids. Their method was to inject microbial cultures down the annulus; where they would metabolize paraffin into alcohols. The range of test well conditions were $32^{\circ}$ to $180^{\circ} \mathrm{F}, 0$ to $20 \%$ salinity, and 3 to $11 \mathrm{pH}$. They reported a field test in which wells were having monthly hot oiling, costs were reduced 15 to $25 \%$ and higher sustained oil production resulted. For microbial methods to be effective, they recommended the following precautions: (1) the microbial method should be applied in well with water cuts in excess of $1 \%$, (2) application of the microbial method in flowing wells should be avoided, (3) high fluid levels can be detrimental to the application of microbial methods, and (4) hydrogen sulfide, certain oilfield chemicals and high salinity can inhibit bacterial activity, therefore microbial methods should not be applied under conditions 2, 3 and 4 . 
Micro-Bac International Inc. estimated that 2,500 to 3,000 wells have been treated using their microbial products and discussed several case histories of microbial wellbore cleanup (Schneider, 1990). Oil production increases have occurred in about $50 \%$ of all wells treated. In certain instances, microbial injection in a near-wellbore region can rival certain existing chemical treatments, both in efficiency and cost (Pelgar, 1990). Other companies involved in the application of microbial method for wellbore cleanup are: Alpha Environmental, Microbial System Corporation, Microbios Ltd., Geo-Microbial Technologies, Inc. National Paraclean, Universal Paraclean, Inc. and PSL, Inc. (American Oil \& Gas Reporter, 1991).

Santamaria and George (1991) recently published a paper in which they gave results of microbial treatment of five production wells. These wells have severe paraffin deposition problems and had to be controlled with hot oiling at least every two week. A microbial formulation and biocatalyst were injected down the annulus weekly or every other week, depending on the severity of the paraffin problem. They concluded that the production rates of oil, water, and gas were not increased by use of the microbial treatment. However, the production down time due to hot oiling was reduced by microbial treatments. During the microbial treatment, no hot oiling was required for six months. Microbial treatments for paraffin reduction have potential but will generally be limited to wells with certain characteristics, since the treatment consists of living microorganisms. Well characteristics cited in particular include bottomhole temperatures less than 180 to $210^{\circ} \mathrm{F}$, salinity as sodium chloride less than $20 \%$, and the absence of any well treating chemicals such as biocides or corrosion inhibitors in that well during treatment.

\section{PROCEDURES IN TREATING A PARAFFIN PROBLEM}

Removal of wax from wells and flowlines can account for significant additional operating costs. If possible, a well should be operated in such a way that paraffin deposits are minimized. The operating conditions that allow waxes to precipitate in the wellbore must be identified, and deposition rates must be estimated to determine the costs associated with the removal of wax deposits. Weingarten and Euchner (1988) outline laboratory tests and analyses that may be used to characterize any type of oil to define the conditions under which waxes will precipitate. 
If a paraffin problem occurs, the following suggestions of how to attack a paraffin problem may be of assistance to the operator. They are drawn from Brock (1989), and McCall and Johnson (1984), and Thomas (1988).

1. Determine the nature of the deposit.

(a) Heat sample of the deposit to $125^{\circ}$ to $150^{\circ} \mathrm{F}$; most paraffins will melt.

(b) Place in water, paraffins and asphaltenes float.

(c) Place in hot xylene; paraffins asphaltenes dissolve.

(d) Place in pentane or gasoline; paraffin dissolves.

(e) Place in acid; iron oxide and iron sulfide dissolve.

2. Decide if the expense of mechanical treatment, hot oiling or solvent application is justifiable.

3. Test various products for their effect on the paraffin forming characteristics of the crude, and their compatibility with formation fluids and with other well treatment products. Hot and cold flask tests are used to check for the effectiveness of detergents and dispersants in breaking up and dispersing paraffin samples. If a paraffin inhibitor seems to be called for, measure cloud point depression and pourpoint depression. Test all selected additives for compatibility with produced fluids, and other treating fluids. Test additives for emulsifying properties with produced fluid, and test that it leaves surfaces water-wet.

4. Select a product for field testing and design a treatment procedure.

5. Apply the test method. Insure adequate contact time with the paraffin deposit. Check for proper concentration and mixing of additive. If possible, preclean the system of paraffin deposits before other treatments (eg. for scale, corrosion) are applied.

6. Monitor results, especially comparing with the results of no treatment, and compare with results of the usual clean up methods, if any.

7. Evaluate economics; if promising, expand treatment to more wells. If still promising, expand to a comprehensive treatment. But at the same time, be flexible and try to be aware of new products being introduced to the market.

Thomas (1988) reminds us that effectiveness depends on a thorough and complete evaluation of the causes of the problem and the needs of the field. Attention must be given to the fact that 
multiple problems may be occurring at the same time and that the needs of the field may be dictated by economics. Thus, the use of paraffin control chemicals is not a complete cure all for paraffin problems.

Brown (1940) listed the methods used by oil producers in order of popularity. This list does not seem to have changed much from his time to the present, except that open fire and toxic chemicals are seldom used and the chemicals used for paraffin treatments are much improved. Laboratory testing and evaluation have also become an integral part of the paraffin treatment process.

A. From tubing of flowing wells:

1. Use wire-line scraping tools.

2. Use automatic scrapers or darts.

3. Use stopcock tlowing and purging.

B. From tubing of pumping wells:

1. Pull rods.

2. Use commercial solvents and softeners.

3. Pull tubing and steam it.

C. From flow lines:

1. Burn crude oil in bell holes under lines.

2. Purge lines by opening chokes and flowing wells.

3. Flush lines with steam.

4. Circulate hot water, kerosine, or gasoline through lines.

D. From stock tanks:

1. Clean tanks, disposing of sediment by spreading on lease roads or burning in pits.

2. Reclaim through heating plants.

3. Use dispersants or solvents.

E. From sand face or liner section:

1. Use batch treatments of heat-generating chemicals, commercial solvents or softeners, hot water or gasoline.

2. Use steam. 


\section{ENVIRONMENTAL CONCERNS IN WELL TREATMENT FOR PARAFFIN PROBLEMS}

Treatment of wells for solving paraffin problems usually involves injecting relatively small quantity of chemicals, heated oil or heated water into a producing well, and as such is not regulated by existing state and federal regulations. However, injecting chemicals such as calcium carbide, chlorinated hydrocarbon, etc. which are designated as hazardous substances under section 102(a) of the Comprehensive Environmental Response, Compensation and Liability Act, should be avoided for treatment of paraffin paraffin problems.

\section{SUMMARY AND CONCLUSIONS}

Paraffin deposition has been a problem for operators in many areas since the beginning of petroleum production from wells. Most crude oil has a cloud point which is the temperature at which wax forms. The temperature in the reservoir is usually above ambient, and as petroleum is produced, it cools. If it cools below its cloud point it begins to deposit wax on the walls of the production equipment. This deposit reduces and sometimes stops production.

The most common way of treating the problem is by periodic hot oiling of the offending well as soon as the production falls a given amount below the projected decline curve. This process may need to repeated as often as once a week. The oil is often taken from a tank on the lease and heated, and usually the hot oil is applied down the annulus between the string and the casing. Since the produced paraffin tends to settle at the bottom of the stock tanks, this procedure may lead to the re-introduction of a large amount of wax to the well, and perhaps even to the formation. Hot xylene treatments avoid the reintroduction of wax to the well and do a good job of cleaning, but are more expensive. The hot oiling process was developed because the application of heat is the most economical method of removing deposits; and if the temperature is kept high enough, heat will prevent the formation of deposits. Unfortunately, hot oil treatments tend to build up paraffin at the sand face leading to formation damage.

Surfactants in conjunction with heat or solvents give satisfactory cleanout performance. There is growing evidence that dispersants and inhibitors are useful in helping to prevent the deposition of paraffin. These agents can be applied along with descaling materials in squeeze processes, or they can be applied in a batch mode down the well bore; or they can be bled into the production stream through small tubing added for this purpose; inhibitors can be added down hole as solids. Even though the best results may be obtained by constant application of reagents, 
operators are reluctant to run small-diameter tubing which needs to be attached to production tubing, since this may require an additional expense in pulling and running tubing, as well as being inconvenient in servicing the well.

Dispersants and crystal modifiers are very specific, and maximizing the effectiveness of these agents requires screening of a rather large number of potential candidate materials.

The effectiveness of paraffin treatment depends on a thorough and complete evaluation of the causes of the problem and the needs of the field. When chosen correctly and applied correctly, paraffin treating products can help control and manage a paraffin problem. Attention must be given to the facts that multiple problems may be occurring at the same time and that the needs of the field may be dictated by economics. Thus, the use of paraffin control chemicals is not a complete cure for all paraffin problems. Shock et al. (1955) concluded that there is no single, simple method for prevention or control of paraffin accumulation. The variety of treatment methods is evidence of this fact.

\section{Recommendations and Areas for Further Study}

Shock et al. (1955) recommended that the paraffin problem should be re-examined and better classified on an industry-wide basis. There was a need for the development of systems which will evaluate and classify the potential paraffin forming tendency of a crude. Viscosity-temperature curves of systems of known composition approach this criterion, showing the difference between the behavior of normal paraffin containing crude, asphaltene containing crude, and viscous water emulsions.

In discussions about the state of the art with experts in the field, two problem areas were emphasized. The first is the difficuity of obtaining representative samples of wax and especially of oil for testing purposes. Oil samples often came from a tank which contained the production of several wells, and may not represent the composition of the oil in equilibrium with the troublesome wax deposit. Since the composition of wax and oil is different at different parts of the field, and at times, even at different locations of a given well, the difficulty of obtaining repres $f$,ntative samples becomes evident. If the operator who has paraffin problems would take a bit more care in obtaining good samples, the service companies could do a better job in assisting him.

The other problem area discussed lies in the deposition tests themselves. The standard deposition tests are quite non-reproducible, especially the cold finger test. Comparisons of products must be done side by side so that a relative ranking may be obtained, rather than obtaining 
a valid numerical result that can be used for comparison purposes. There is need for a deposition test that is faster and much more reproducible so that if a sample is run today, and the same sample is run in a week, a month, a year, the results will be the same. Also, the cold finger test only determines deposition of paraffin by the molecular diffusion mechanism, and is usually carried out with no brine in the system. There is a need for a test in which the oil is below its cloud point which will determine the rate of wax deposition, especially in the presence of brine. Once the tests are reproducible and represent conditions as they exist in the field, results of the deposition test can be correlated with composition of the crude.

Cloud points are often determined by measuring temperature as a function of viscosity. A differential scanning calorimeter (DSC) might be used to to determine the point of first wax crystal formation, and compared with ASTM cloud point and viscosity tests. The method may well be faster and more reproducible than using viscosity and visual observation of the cloud point. In addition, it may provide further information on the behavior of crude oil as it cools. It should give information on the action of wax crystal modifiers.

Visualization techniques show promise of being very helpful. A visual polarizing microscope attached to a video camera and a VCR can be used to view the type of crystals and paraffin masses which accumulate on cooling, with and without additives. These observations need to be correlated with other tests such as composition studies by gas chromatography, DSC, viscosity, and depositional behavior.

Although there are a few reports in the literature on prevention or treatment of paraffin by microbial techniques, additional work is needed. An opportunity exists for the development of this technique.

\section{ACKNOWLEDGMENTS}

The author acknowledges the financial support of this work provided by the U.S. Department of Energy under Cooperative Agreement DE-FC2283FE-60149. The author would like to thank Bonnie Gall, Phil Lorenz, Paul Stapp and Bill Linville for their critical review of this report. 


\section{BIBLIOGRAPHY}

Addison, G.E. Paraffin Control more Cost Effective. SPE 13391. Eastern Regional Meeting, Charleston, WV Oct. 31- Nov. 4, 1984.

Agrawal, A.G., R.C. Purohit, M. Surianarayanan, G.C. Joshi, and R. Krishna. Influence of waxes on the flow properties of Bombay High Crude. Fuel, v. 68, 1989, pp 937-939.

Agrawal, A. G., H. U. Khan, M. Surianarayanan, and G. C. Joshi. Wax Deposition of Bombay High Crude Oil Under Flowing Conditions. Fuel, v. 69, 1990, pp 794-796.

Amer. Oil \& Gas Reporter, Mar. 1989 pp. 29-36.

Amer. Oil \& Gas Reporter, to be published, 1991.

Ashford, J.D., C. G. Blount, H. A. Marcou, H. M Ralph, and E. W.Skaalure. Annular Packer Fluids for Paraffin Control: Model Study and Successful Field Application. SPE 19730. SPE Prod. Eng., Nov., 1990, pp. 351-355.

Ashton, J. P., L. J. Kirspel, H. T. Nguyen and D. J. Credeur. In-Situ Heat System Stimulates Paraffinic Crude Producers in the Gulf of Mexico. SPE 15660. 61st Annual SPE Annual Technical Conference, New Orleans, LA Oct. 5-8, 1986.

Barker, K. M. Formation Damage Related to Hot Oiling. SPE Prod. Eng. Nov. 1989, pp. 371375. SPE 16230

Barker, K. M., G. E. Addison, and J. E. Cunningham. Disadvantages of Hot Oiling for Downhole Paraffin Removal in Rod Pumping Systems. Southwestern Petroleum Short Course, 1984, 399-406.

Beyer, A. H. and D. E. Osborne. Downhole Emulsification for Improving Paraffinic Crude Production. SPE 2676, Denver, Colo. Sept. 28-Oct. 1, 1969.

Bilderback, C. A. and L. A. McDougall. Complete Paraffin Control in Petroleum Production $J$. Pet. Tech., Sept. 1969, pp. 1151-1156.

Billingsley, D. L. How to Control Paraffin in Shallow Pumping Wells. World Oil, July 1963, pp. 90-91. 
Bishop, M. D. and D. R. Woodward. Biological Paraffin Treatment Programs. Southwest Petroleum Short Course, 1990.

Brock, Ronn. An Experimental Paraffin Control Treatment Procedure. Southwestern Petroleum Short Course, 1989, pp 91-106.

Brod, M., B. C. Deane and F. Rossi. Field Experience with the Use of Additives in the Pipeline Transportation of Waxy Crudes. J. Inst. Petrol., v 57, 1971, pp. 110-116.

Brown, W. Y. Prevention and Removal of Paraffin Accumulations. Drill. and Prod. Pract., API 1940, pp 85-96.

Bucaram, S. M. An Improved Paraffin Inhibitor. J. Pet. Tech., Feb 1967, pp. 150-156.

Burger, E. D., T. K. Perkins, and J. H. Striegler. Studies of Wax Deposition in the Trans Alaska Pipeline. J. Pet. Tech., June 1981, pp. 1075-1086. SPE 8788.

Carnahan, Norman F. Paraffin Deposition in Petroleum Production. J. Pet.Tech., Oct. 1989, p.1024. SPE 19895.

Charles, J. G. Paraffin Inhibition Treatments Reduce Well Maintenance Costs. SPE 13362, Eastern Regional Meeting, Charleston, WV Oct. 31 - Nov. 4, 1984.

Cheng, C. M. An Empirical Study of the Impact of Hot Oiling on Utikuma Lake Productivity. CIM/AOSTRA 1991 Technical Conference, Banff Alberta, Apr. 21-24, 1991.

Cole, R. J. and F. W. Jessen. Paraffin Deposition. Oil \& Gas J. Sept. 19, 1960, pp. 87-91.

Coppel, Claude. Chevron. Private communication.

Davis, J. S. and I. P. Fanaritis. Insulated Tubing Can Cut Wellbore Heat Losses. Oil \& Gas J., Mar. 1, 1982, Fp. 86-96.

The Electrothermic Company, Advertising literature.

Enhanced Recovery Week, Oct. 24, 1988 pp. 2-3. IROC to break paraffins with electric heating in Kansas. 
Garbis, S. J., H. R. Olsen, M. C. Cushner, and G. T. Woo. A Novel Technique for Paraffin Problems - A Field Study in the Ackerby Dean Unit, Dawson County Texas. Southwestern Petroleum Short Course, 1984, pp. 440-448.

Gavlin, G.,E. A. Swire, and S. P. Jones. Pourpoint Depression of Lubricating Oils. I\&EC, v. 45, 1953, pp. 2327-2335.

Gdanski, R. Paraffin Problems in Low Paraffin Content Crude Southwestern Petroleum Short Course, 1984, pp. 449-456.

Going, W. S.. Inhibitor Treatment by Coil Tubing Unit Can Now Be Performed While Maintaining Production. SPE 18891. SPE Production Operations Symposium, Oklahoma City, OK Mar. 13-14, 1989.

Green, Robert S. Transportable System for Providing Heat to Flowing Materials. US 4,720,263 Jan. 19, 1988.

Hales, M. Thermally Insulated Pipelines Successfully Move High-Wax-Content Crude Offshore Gabon. Oil \& Gas J., Jan 25, 1982, pp. 179-186.

Haynes, H. H. and G. L. Lederman. Cost-Effective Paraffin Inhibitor Squeezes Can Improve Production Economics. SPE 15178, Billings, MT. May 19-21, 1986.

Hicks, G. A. Uniform Program Reduces Paraffin Removal Costs. Oil \& Gas J., f ug. 20, 1990, pp.85-90.

Hiebert, G. (Baker Chemlink) Private communication, 1991.

Howell, James N. and F. W. Jessen. Determination of the Viscosity-Temperature Relationship for Crude Oils with the Ultra-Viscoson. J. Pet. Tech., Sept. 1956, pp. 95-97.

Hunt, Jr., E. B. Laboratory Study of Paraffin Deposition. J. Pet. Tech., Nov. 1962, pp. 12591269.

Hunt, William C. III. Cyclic Thermal Solvent Recovery Method Using Visbroken Produced Crude Oil. US 4,465,138, Aug. 14, 1984.

Jessen, F. W. and James N. Howell. Effect of Flow Rate on Paraffin Accumulation in Plastic, Steel, and Coated Pipe. Pet. Trans. AIME, v. 213, 1958, pp.80-84. 
Jorda, R. M. Parấfin Deposition and Prevention in Oil Wells. J. Pet. Tech., Dec. 1966, 16051612.

Marsden, S. S and R. Raghavan. A System for Producing and Transporting Crude Oil as an Oil/Water Emulsion. J. Inst. Petrol., v. 59, Nov. 1973, pp. 273-278.

Matloch, W. J. and M. E. Newberry. Paraffin Deposition and Rheological Evaluation of High Wax Content Altamount Crude Oils. SPE 11851. Rocky Mountain Regional Meeting, Salt Lake, UT, May 23-25, 1983.

McCall, Jr., J. M., and R. L. Johnson, II. Paraffin Treatment in the Well Service Industry. Southwestern Petroleum Short Course. 1984, pp. 457-464.

McAuliffe, C. D., R. Simon, and C. E. Johnson, Jr. Method of Pumping Viscous Crude Oil. US 3,380,531, Аpi. 30́, 1968.

McAuliffe, C. D., R. Simon, and C. E. Johnson, Jr. Pumping Viscous Crude . US 3,467,195, Sept. 16, 1969.

McClaflin, G. G. and D. L. Whitfill. Control of Paraffin Deposition in Production Operations. J. Pet. Tech., Nov. 1984, pp 1965-1970. SPE 12204.

Mendell, J. L and F. W. Jessen. Paraffin Inhibition and Flow Improvement in Crude Oil Systems. I. Canad. Pet. Tech., Apr.-Jun. 1972 pp. 6C-66.

Mills, R. Van A. The Paraffin Problem in Oil Wells. BuMines RI, Serial No. 2550, Dec, 1923, $11 \mathrm{pp}$.

Nathan, C. C. How to Evaluate Paraffin Inhibitors. The Petroleum Engineer, Nov. 1955, pp. B66 / B-68.

Nathan, C. C. Solubility Studies on High Molecular Weight Paraffin Hydrocarbons Obtained from Petroleum Rod Waxes. Petroleum Trans. AIME, 1955, v. 204, pp. 151-155. TP 4122.

Newberry, M. E Chemical Effects on Crude Oil Pipeline Pressure Problems, J. Pet. Tech. May 1984, pp. 779-786.

Newberry, M. E. and K. M. Barker. Formation Damage Prevention Through the Control of Paraffin and Asphaltene Deposition. SPE 13796, 1985. 
Pattan, C. C. Paraffin Deposition from Refines Wax-Solvent Systems. SPEJ., March 1970, pp. 17-24.

Pelgar, J. MEOR Research on Wellbore Stimulation, Pres. at the International Conference on Microbial Enhanced Oil Recovery, Norman, OK, May 23-31, 1990.

Porter, Roy E., consultant , Priyate communication 1990.

Price, R. C. Flow Improvers for Waxy Crudes. J. Inst. Petrol., v. 57, Mar. 197 i, pp. 106-109.

Rahimi, A. B. Halliburton, Duncan, OK. Private communication 1991.

Reistle, Jr., C. E. Methods of dealing with Paraffin Troubles Encountered in Producing Crude Oil. BuMines Technical Paper 414, 1928, 39 pp.

Reistle, Jr., C. E. and O. C. Blade. Paraffin and Congealing-Oil Problems. BuMines Bulletin $348,1932, .171 \mathrm{pp}$.

Santamaria, M. M., and R. E. George. Controlling Paraffin-Deposition-Related Problems by the Use of Bacteria Treatments. Pres. at the 66th Annual Technical Conference and Exhibition of the SPE, Dallas, TX, Oct. 6-9, 1991. SPE 22851.

Santamaria, M. M., R. B. Roberts and S. K. J. Gill. Evaluation of Paraffin Deposition Potential Using Drillstem Test Fluids. Paper pres. at the Production Operations Symposium held in Oklahoma City, April 7-9, 1991. SPE 21713.

Schneider, D. R. Micro-Bac Internationa!, Inc., 1990.

Schuldiner, Jacob A. Identification of Petroleum Products by Chromatographic Fluorescence Methods. Anal. Chem, v. 23, 1951, pp. 1676-1680.

Settineri, R. M. Method for Removing or Retarding Paraffin Build-Up on Surfaces in Contact with Crude Oil. US 4,455,175, Jun. 19, 1984.

Shock, D. A., J. D. Sudbury, and J. J. Crockett. Studies of the Mechanism of Paraffin Deposition and its Control. J. Pet. Tech., Sept. 1955, pp. 23-28.

Sifferman, T. R. The Flow Properties of Difficult to Handle Waxy Crudes. SPE 7409, Houston, TX, Oct. 1-3, 1978. 
Simon, R. and W. G. Poynter. Down-Hole Emulsification for Improving Viscous Crude Production. J. Pet. Tech., v. 20, Dec. 1968, 1349-1353.

Slater, G. and A. Davis. Pipeline Transportation of High Pourpoint New Zealand Crude Using Pourpoint Depressants. SPE 15656, 61st Annual, New Orleans, LA, Oct. 5-8, 1986.

Spitzer, W. R. Plug for use in Hot Oil Treatment of Wells Having Paraffin Deposits and Method of Use Thereof. US 4,655,285, Apr. 7, 1987.

Stine, Laurence O. Method for In Situ Conversion of Hydrocarbonaceous Oil. US 4,444,257, Apr. 24, 1984.

Straub, T. J. An Investigation Into Practical Removal of Downhole Paraffin by Thermal Methods and Chemical Solvents. SPE 18889. SPE Production Operations Symposium, Oklahoma City, OK, Mar. 13-14, 1989.

Sutton, G. D. and G. D. Roberts. Paraffin Precipitation During Fracture Stimulation. J. Pet. Tech., Sept., 1974, pp. 997-1004. SPE 4411.

Svetgoff, J. Paraffin Problems Can Be Resolved With Chemicals. Oil \& Gas J., Feb. 27, 1984, pp. 79-82.

Thierheimer, Jr. Charles. L. Solvent for Paraffin Removal from Oilfield Equipment. US 4,925,497, May 15, 1990.

Thomas, D. C. Selection of Paraffin Control Products and Applications. SPE 17626. SPE Int. Meeting, Tianjin, China, Nov. 1-4, 1988.

Tuttle, Robert N. High-Pour-Point and Asphaltic Crude Oils and Condensates. J. Pet. Tech., June, 1983, pp. 1192-1196. SPE 10004.

Uhde, A. and G. Kopp. "Pipeline Problems Resulting from the Handling of Waxy Crudes". J. Inst. Petrol., v. 57, Mar. 1971, pp. 63-73.

Uren, Lester Charles. Petroleum Production Engineering - Oil Field Exploitation. McGraw-Hill, NY, 1953, pp 411-415. 
van Engelan, G. P., C. L. Kaul, B. Vos, H. P. Aranha. Study of Flow Improvers for Transportation of Bombay High Crude Oil Through Submarine Pipelines. J. Pet. Tech., Dec. 1981, pp. 2539-2544.

Wagner, R. D. Paraffin Chemical Treatment vs. Hot Oiling in Subsurface Hydraulic Wells. SPE 18890. SPE Production Operations Symposium, Oklahoma City, OK Mar. 13-14, 1989.

Weingarten, J. S. and J. A. Euchner. Methods for predicting Wax Precipitation and Deposition. SPE Prod. Eng., Feb. 1988, pp. 121-126.

Whitley, O. D. and J. B. Poque. Pressure Differential Circulating Valve. US 4,527,629, Jul. 9, 1985.

Won, K. W. Thernodynamics for Solid Solution-Liquid-Vapor Equilibria: Wax Phase Formation from Heavy Hydrocarbon Mixtures. Fluid Phase Equilibria, v. 30, (1986), pp. 265-279.

Woo, G. T., S. J. Garbis and T. C. Gray. Long Term Control of Paraffin Deposition. SPE 13126. 59th Annual SPE Technical Conference, Houston, TX, Sept. 16-19, 1984.

Wright, J. C. Paraffin Prevention and Removal in Wells in Southeastern Ohio. Drill. and Prod. Pract., API 1951, pp 380-388.

Yukl, Edward T. and Andrew W. Marr, Jr. Process Solves Paraffin Buildup in Tubing. Oil \& Gas J., Aug 8, 1988, pp. 68-70. 

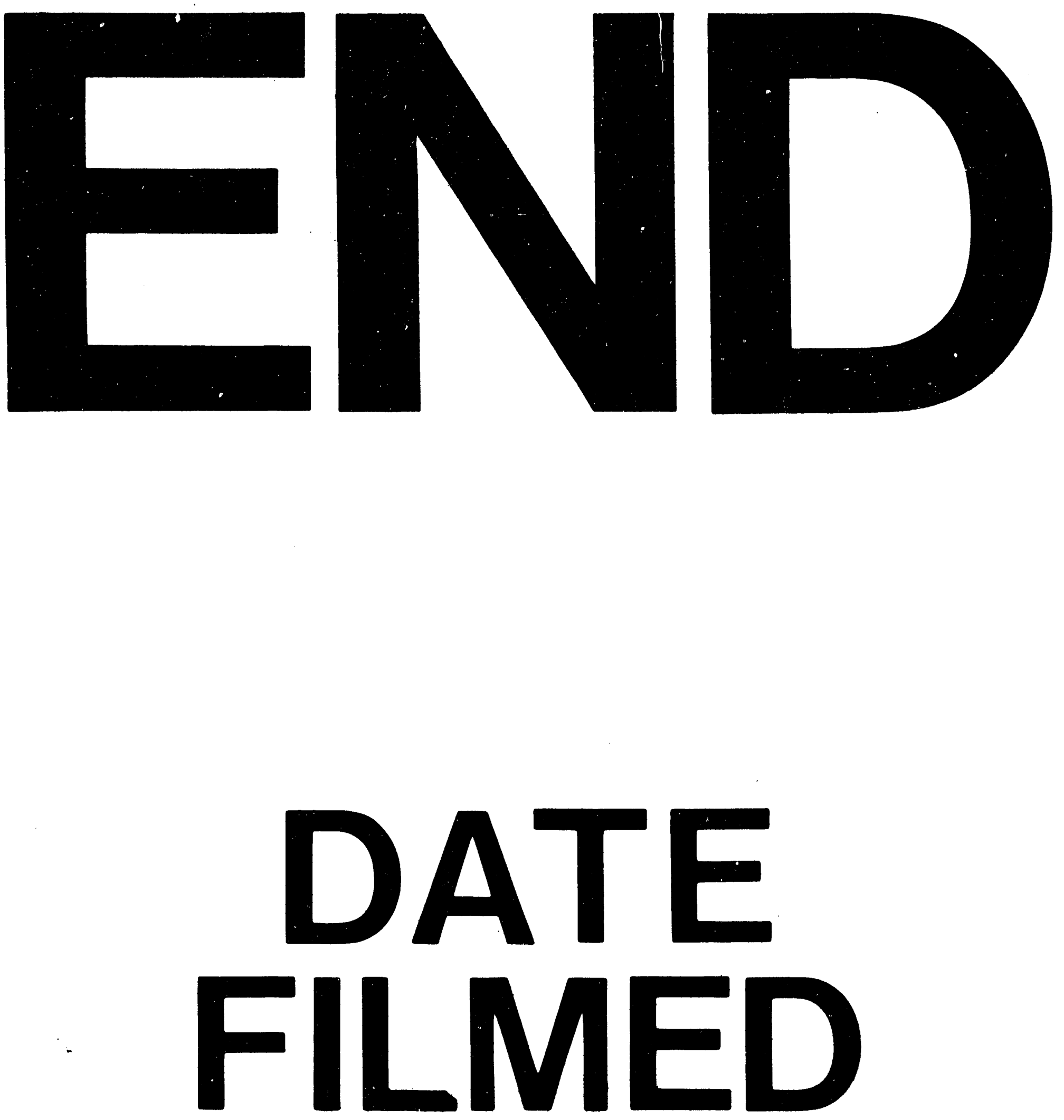

1

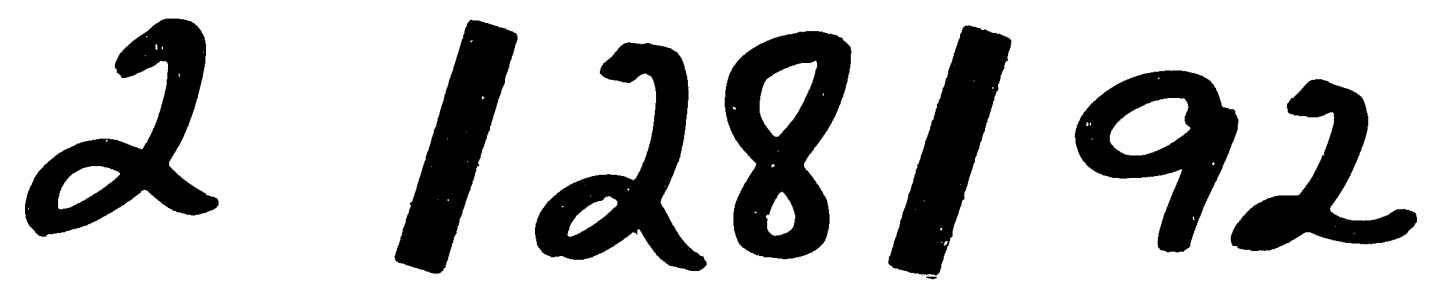




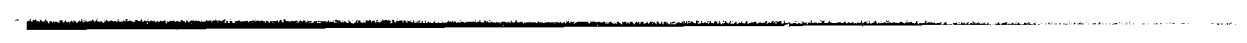

